\title{
SEARCH FOR ARTERIO-VENOUS SHUNTS IN THE RABBIT OVARY IN SITU USING PERFUSION OF MICROSPHERES*
}

\author{
K. AHREN, P. O. JANSON ANd G. SELSTAM \\ Department of Physiology and Department of Obstetrics and Gynaecology, \\ University of Göteborg, Göteborg, Sweden
}

(Received 25th February 1974)

\begin{abstract}
Summary. A technique for perfusion of the rabbit ovary in vivo is described which allows a quantitative determination of the intra-ovarian passage from artery to vein of $15 \pm 5 \mu \mathrm{m}$ non-radioactive microspheres. The passage of microspheres was less than $1 \%$ in ovaries containing follicles (from non-pregnant rabbits) as well as in ovaries containing CL (from rabbits in different stages of pseudopregnancy). Addition of a vasodilator to the perfusion system did not influence the result.

The present results do not indicate that arterio-venous shunts of physiological significance exist in the rabbit ovary.
\end{abstract}

\section{INTRODUCTION}

Experiments with sheep indicate that there are regular changes in ovarian blood flow throughout the cycle (Mattner \& Thorburn, 1969), and experiments in many species have shown that LH produces ovarian hyperaemia. This effect is seen in the rat within a few seconds of the injection of LH (Wurtman, 1964). The mechanisms of these blood flow changes in the ovary are unknown and even the magnitude of the blood flow is a matter of debate (Setchell, 1969; Ahrén, Janson \& Selstam, 1971; Goding, Baird, Cumming \& McCracken, 1971). Marked differences in results have been reported from studies using direct techniques for blood flow determinations, i.e. cannulation of the ovarian vein, and those using indirect techniques, e.g. xenon and krypton dilution methods and indicator fractionation techniques. Direct measurements of the ovarian blood flow in sheep ovaries by timed collection of the venous effluent (Mattner \& Thorburn, 1969) resulted in values which were almost 10 times higher than those obtained by the indirect methods (Setchell, 1969; Brown, Hales \& Mattner, 1973). It has been suggested that this marked difference could be due to arterio-venous shunts in the ovary. The finding that the $\mathrm{O}_{2}$ tension of ovarian vein blood is higher than that of peripheral venous blood has been regarded as favouring the existence of functional arterio-venous shunts in the ovary (Goding et al., 1971).

It was suggested by Pharriss (1970) that a reduction of total ovarian blood

* Reprint requests to: Dr P. O. Janson, Fysiologiska institutionen, Medicinaregatan I1, Fack, 40033 Göteborg 33, Sweden. 
flow might be the initiating mechanism for luteolysis after injection of $\mathrm{PGF}_{2 \alpha}$. Infusions of $\mathrm{PGF}_{2 \alpha}$ into the ovarian artery of the sheep did not, however, reduce the blood flow while there was a marked reduction of progesterone output from the ovaries containing CL (McCracken, Baird \& Goding, 1971). Goding and his co-workers suggested therefore that PGF $_{2 x}$ might cause a redistribution of blood within the ovary restricting the blood flow to the GL. It was suggested that arterio-venous shunts within such an ovary form the structural basis for this blood flow redistribution.

At present, there are few morphological studies of the ovary concerning arterio-venous shunts. Reynolds (1950), using corrosion casts, was able to pass vinylite through the CL of rabbit ovaries from the arterial to the venous side and vice versa. Some authors have also reported histological structures in ovarian vessels which might be compatible with shunt mechanisms (for a review, see Gillet, 1971), and Goding et al. (1971) reported that histological evidence for arterio-venous shunts has been found in sheep ovaries.

In the present study, non-radioactive carbonized microspheres of a diameter somewhat larger than that of erythrocytes were used in perfusion studies to determine whether such microspheres can pass from the arterial to the venous side in rabbit ovaries of different endocrine stages to test the existence of functional arterio-venous shunt vessels. A preliminary report of the experimental system has been published elsewhere (Ahrén et al., 1973).

\section{Animals}

\section{MATERIALS AND METHODS}

Albino virgin rabbits of 5 to 6 months of age and weighing 2.4 to $2.8 \mathrm{~kg}$ were used. They were given a standard diet (Astra Ewo pellets) but not allowed to grow fat, to avoid impeding the surgical procedure. The rabbits were deprived of food 18 to $24 \mathrm{hr}$ before the experiment. Pseudopregnancy was induced by an intravenous injection of 500 i.u. HCG. The age of CL was estimated by the method of Harper (1963).

\section{Chemicals and hormones}

The following were used: HCG (Gonadex: Leo Ltd, Helsingborg); sodium pentobarbitone (Nembutal, $50 \mathrm{mg} / \mathrm{ml}$ : Abbott Ltd) diluted with saline; mepivacaine (Carbocain: Bofors Ltd); heparin (5000 i.u./ml Vitrum Ltd); norepinephrine (Nor-exadrin: Astra Ltd) and papaverine (Sigma Chemicals Company). The cannulae (Venflon, nos 170 and 100) were manufactured by Viggo Ltd and the catheters (Intramedic, PE 10, 50 and 90) by Clay Adams Ltd.

\section{Microspheres}

Non-radioactive, carbonized microspheres, $15 \pm 5 \mu \mathrm{m}$ S.D. in diameter, were obtained from the Minnesota Mining and Manufacturing Company, St Paul, U.S.A. The mean specific gravity of the spheres was 1.4 . They were suspended in $6 \%$ dextran in saline (Macrodex: Pharmacia Ltd) immediately before the experiment with a drop of detergent (Teepol) added to the microsphere suspension to inhibit aggregation. 
Perfusion techniques

Different perfusion techniques for the ovary have been described in the literature. In these investigations, the aim has been to study various aspects of ovarian physiology either with the ovary in situ (perfusion in vivo) or isolated (perfusion in vitro). In the present study two types of perfusion procedures were used in vivo, corresponding to Type II and Type III according to the classification by Ahrén et al. (1971).

Type II perfusion. Nembutal was injected through a cannula into a marginal ear vein, and the anaesthetized rabbit was placed on a heating pad. Under supplementary local anaesthesia, tracheotomy was performed and the abdomen was opened through a mid-line incision. The intestines were held aside and covered with a moistened cloth. The ovaries and their vascular pedicles were dissected free from the surrounding tissues and the vessels were cut between thin ligatures. The vascular anatomy of one ovary and the positions of the ligatures are illustrated in Text-fig. 1. The ligatures were tied at some distance from the main vessels to avoid vasoconstriction. The inferior mesenteric artery was catheterized for infusions of microspheres, norepinephrine, and

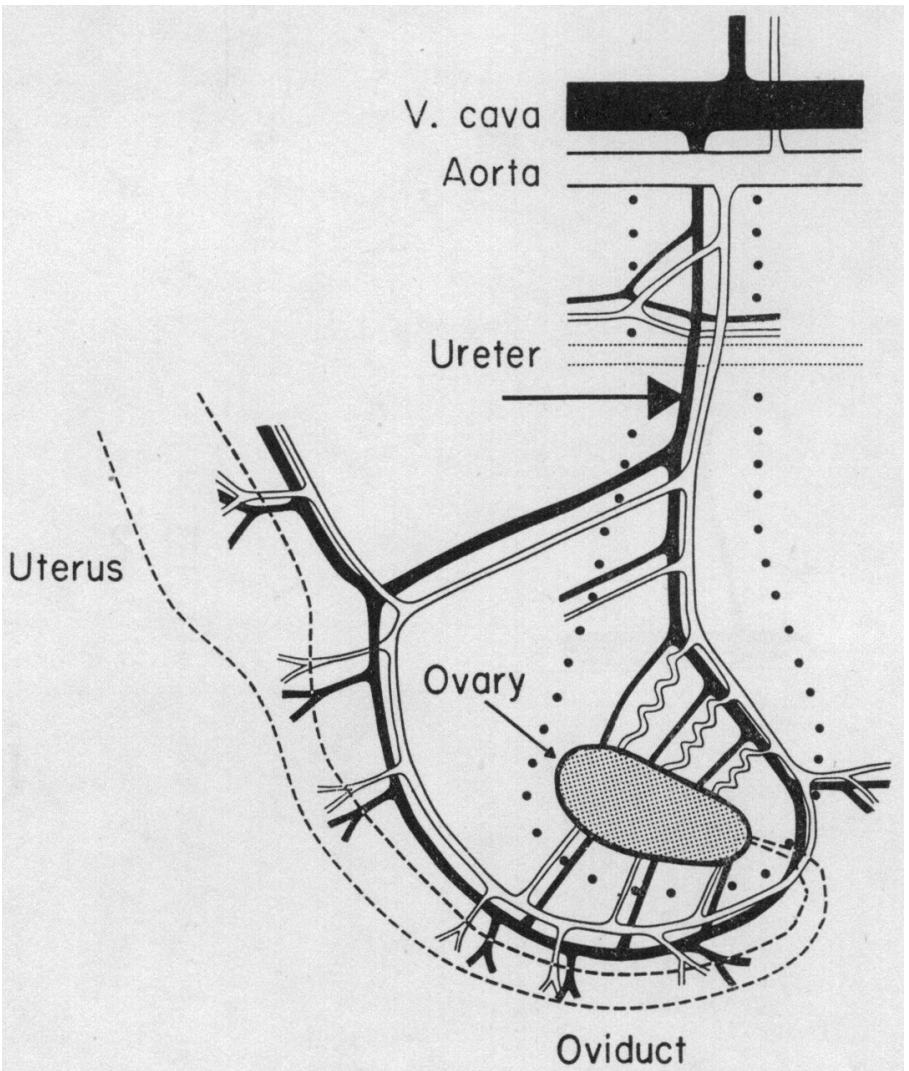

TEXT-FIG. 1. Schematic drawing of the preparation of a rabbit ovary and its vascular pedicle. Thin ligatures were tied as indicated by the dotted lines. Some distance between the ligatures and the ovarian vein was necessary to avoid vascular constriction. Venous catheters were inserted either directly into the ovarian vein, indicated by the arrow, or into the inferior vena cava. 
papaverine into the aortic blood stream above the ovarian arteries. The uteroovarian vein was cannulated for blood collection. During the infusions of microspheres, which lasted approximately $1 \mathrm{~min}$, a clamp was placed on the aorta distal to the origins of the ovarian arteries. At least five 1-min samples of blood from the ovarian vein were taken during and after the microsphere infusion. The samples were shaken vigorously and $20 \mu \mathrm{l}$ from each sample were examined under a microscope for the presence of microspheres.

Type III perfusion. Anaesthesia, laparotomy, and dissection of the ovaries and their vascular pedicles were performed as described above. Sigmoidectomy was performed and a section of the aorta, $1 \mathrm{~cm}$ long, above and below the origins of the ovarian arteries was dissected free from underlying tissues and the lumbar arteries were ligated. The aorta was tied distal to the ovarian arteries and cannulated. The cannula was connected to an infusion flask containing $6 \%$ dextran in saline, giving a perfusion pressure of $75 \mathrm{mmHg}$ in the aorta. The perfusate was at room temperature and was not oxygenated.

The veins were cannulated for collection of the effluent from the ovaries.

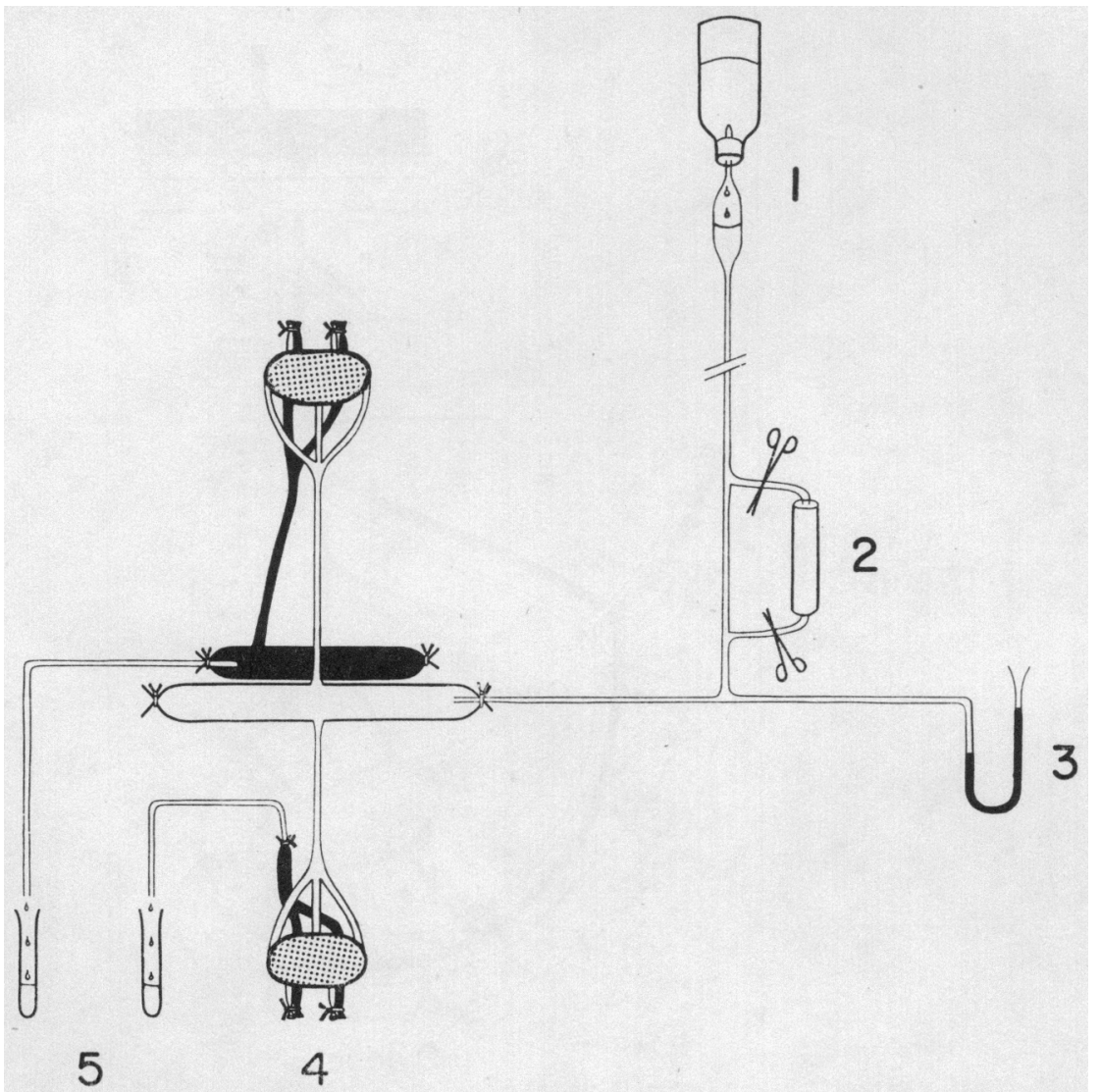

TEXT-FIG. 2. General outline of Type III perfusion system of the rabbit ovary. 1, Infusion flask; 2, parallel coupled tube for introduction of microsphere or erythrocyte suspensions; 3 , mercury manometer; 4 , ovary with ligated vascular connections to uterine and tubal vessels; 5 , collection of venous effluents from right and left ovary. 
Usually, the inferior vena cava could be used for cannulation and collection of perfusate from one ovary while the utero-ovarian vein was used for collection from the other side. Microspheres, erythrocytes, papaverine or norepinephrine were infused through a parallel coupled tube situated just above the aortic cannula which allowed infusions to be made without changing the perfusion pressure. The microsphere suspensions were vigorously shaken before being introduced into the perfusion line. The amount of perfusion fluid infused into the aorta was estimated by means of a drop chamber. The venous effluent was collected in test-tubes and the flow was measured by weighing the testtubes before and after timed collections. The outline of this perfusion system is given in Text-fig. 2. The sequence of the infusions is presented in Flow-sheet 1.

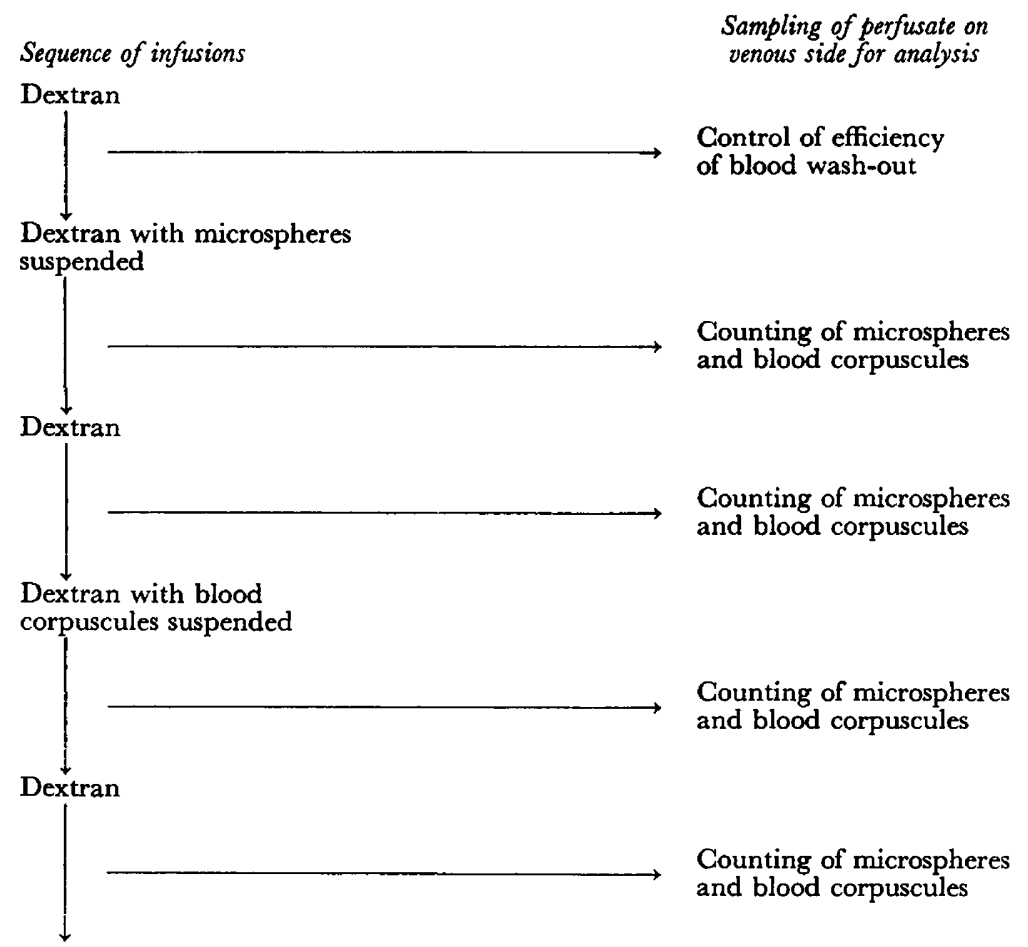

Flow-sheet 1. General experimental procedure of Type III microsphere perfusion of the rabbit ovary.

\section{Microscopic examination of the perfusate}

The venous effluent was shaken for $1 \mathrm{~min}$ in a whirl mixer, and then immediately withdrawn from the fluid with a glass capillary and transferred to a Bürker chamber. This chamber has a depth of $0.1 \mathrm{~mm}$ and can be divided into sub-units of volume by a square system. The microspheres or erythrocytes appeared randomized and showed no tendency to aggregate or to adhere to the edges of the chamber. Microspheres were easily distinguishable from blood cells.

The concentration of microspheres in the suspensions infused into the aorta 
was determined in the same way. Passage of the suspensions through the catheters, syringes, cannulae or tubes used in the preparation had no effect on the microsphere concentration.

To quantify the arterio-venous passage of microspheres in the Type III perfusions, the quotient between microsphere concentrations in the venous effluent and arterial perfusate was calculated, assuming a complete recovery of the perfusate on the venous side.

\section{Type II perfusions}

\section{RESULTS}

In three pseudopregnant rabbits, one with 4-day-old and two with 12-dayold CL, microsphere suspensions of approximately $1000 \mathrm{microspheres} / \mu \mathrm{l}$ in $6 \%$ dextran were infused into the abdominal aorta at a rate of $1 \mathrm{ml} / \mathrm{min}$ for $1 \mathrm{~min}$. The venous effluent blood from four ovaries was collected both during, and for $5 \mathrm{~min}$ after, the microsphere infusion. No microspheres were found in the venous blood from any of the ovaries.

In two of the rabbits mentioned above, $1 \mathrm{mg}$ papaverine was infused into the aorta immediately before the infusion of microspheres. An increase in flow rate in the ovarian vein of 10 and $13 \%$ was noted, but no microspheres were observed in the venous blood. Addition of $100 \mu \mathrm{g}$ norepinephrine to the aortic blood stream after the infusion of microspheres resulted in a rapid and marked reduction in blood flow (98 and $99 \%$ at $2 \mathrm{~min}$ ), lasting approximately $5 \mathrm{~min}$.

This type of perfusion preparation was also attempted in rabbits which had only follicles in the ovaries but the flow in the venous catheter became too low to be adequately measured with the present technique.

\section{Type III perfusions}

Ovaries with follicles. The flow rate of the perfusate remained constant as long as the pressure was kept unchanged. The ovary rapidly blanched and there was a negligible leakage of perfusion fluid to other vascular regions or into the abdominal cavity. A slight oedema gradually developed in the fat of the vascular pedicle. The retention of fluid in the tissues was small compared to the total volume infused into the ovarian artery and was therefore disregarded in the calculations.

When 1 to $2 \mathrm{ml}$ of a suspension containing 108 to 220 microspheres/ $\mu \mathrm{l}$ were infused into the aorta, a reduction of the perfusion flow was seen (Table 1). The mean concentration of microspheres in the venous perfusate was $0.30 \%$ of that of the suspension infused into the aorta. After the infusion of microspheres, the perfusion continued with dextran and was then changed into a blood cell suspension of approximately $5 \%$. The clear venous effluent then turned red and opalescent within a few seconds. No changes in flow rate were observed. When pure dextran was infused again, the perfusate in the veins rapidly cleared. In one rabbit, papaverine mixed with the dextran solution in a concentration of $1 \mathrm{mg} / \mathrm{ml}$ was infused into the preparation during a $10-\mathrm{min}$ period at a constant pressure of $75 \mathrm{mmHg}$ before the perfusion with microspheres. The flow rate remained unchanged and no microspheres were observed in the ovarian venous blood of this rabbit. 


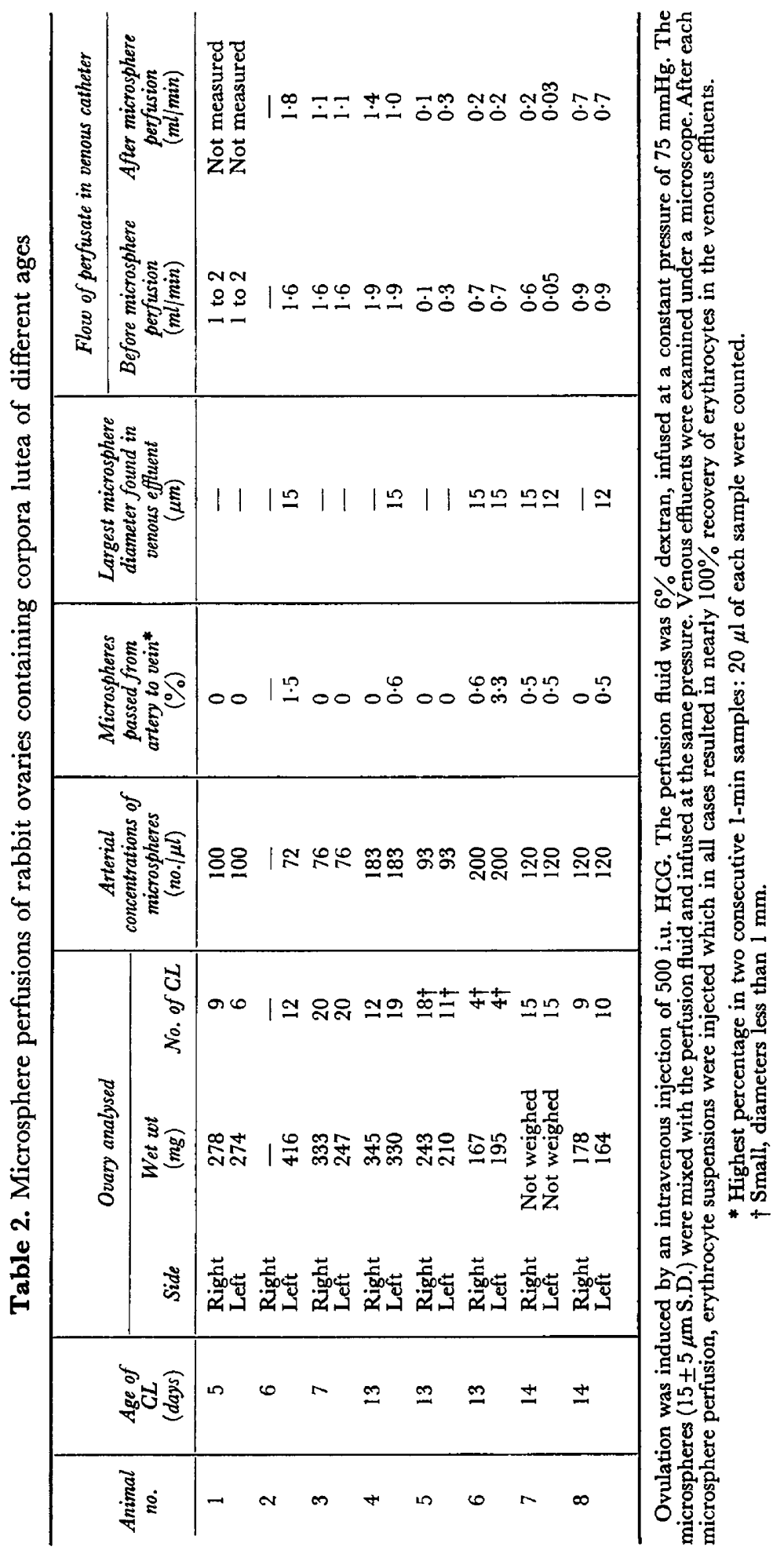


Table 1. The effects of perfusions of microspheres into rabbit ovaries containing follicles

\begin{tabular}{c|c|c|c|cc}
\hline $\begin{array}{c}\text { Wet wt } \\
\text { of ovaries } \\
(\mathrm{mg})\end{array}$ & $\begin{array}{c}\text { Arterial } \\
\text { concentrations } \\
\text { of microspheres } \\
(\text { no. } / \mu \mathrm{l})\end{array}$ & $\begin{array}{c}\text { Microspheres } \\
\text { passed from } \\
\text { artery to vein* } \\
(\%)\end{array}$ & $\begin{array}{c}\text { Largest microsphere } \\
\text { diameter found in } \\
\text { venous effluent } \\
(\mu \mathrm{m})\end{array}$ & $\begin{array}{c}\text { Flow of perfusate in venous } \\
\text { catheter }\end{array}$ \\
\hline $70.8 \pm 8.4$ & 108 to 220 & $0.30 \pm 0.14$ & $\begin{array}{c}\text { Before } \\
\text { microsphere } \\
\text { perfusion } \\
(\text { ml/min })\end{array}$ & $\begin{array}{c}\text { After } \\
\text { microsphere } \\
\text { perfusion } \\
(\mathrm{ml} / \mathrm{min})\end{array}$ \\
\hline
\end{tabular}

Values are given as means \pm standard error of the means of seven ovaries from four rabbits.

The perfusion fluid, $6 \%$ dextran, was infused at a constant pressure of $75 \mathrm{mmHg}$. Microspheres ( $15 \pm 5 \mu \mathrm{m} \mathrm{S.D.)} \mathrm{were} \mathrm{mixed} \mathrm{with} \mathrm{the} \mathrm{perfusion} \mathrm{fluid} \mathrm{and} \mathrm{infused} \mathrm{at} \mathrm{the} \mathrm{same} \mathrm{pressure.} \mathrm{Venous} \mathrm{effluents}$ were examined under a microscope. After each microsphere perfusion, erythrocyte suspensions were injected which in all cases resulted in nearly $100 \%$ recovery of erythrocytes in the venous effluent.

* Highest percentage in two consecutive 1-min samples: $20 \mu \mathrm{l}$ of each sample were counted.

In one rabbit, the perfusion pressure was raised to about $1000 \mathrm{mmHg}$ at the end of the experiment resulting in the passage of $33 \%$ of the microspheres. After this high pressure perfusion, however, some extravasation of erythrocytes took place and it was not possible to wash out blood cell suspensions from these ovaries.

Ovaries with corpora lutea. The perfusion flow was larger than in ovaries with follicles, but the pattern of flow changes after the perfusions of microspheres was the same (Table 2), except for one rabbit (No. 2), in which a small increase was observed. In Rabbit no. 8, papaverine was given in the same way as to the rabbit with ovaries containing follicles described above. No change in the flow rate was seen, even when $100 \mu \mathrm{g}$ norepinephrine were added to the perfusate in Rabbit no. 2 at the end of the experiment.

After perfusion of microspheres, the CL appeared darker than the interstitial tissue, indicating a higher flow rate in this compartment. The mean percentage of microspheres found in the venous effluent from ovaries with CL was $0.5 \%$. Erythrocytes easily passed through and could be washed out from the vascular bed after perfusions of microspheres. In Rabbit no. 6, an increase of perfusion pressure to $1000 \mathrm{mmHg}$ in the aorta resulted in a passage of microspheres of $28 \%$. It was not possible to wash out blood cells after this perfusion. In one rabbit with 14-day-old CL, not shown in the Tables, perfusion of a blood cell suspension at a pressure of more than $300 \mathrm{mmHg}$ resulted in a massive extravasation of erythrocytes which was verified on histological examination.

\section{DISCUSSION}

Unlabelled microspheres have been used to study arterio-venous shunt vessels in various organs (intestine: Grim \& Lindseth, 1958; skeletal muscle: Piiper \& Rosell, 1961; kidney, lung, liver: Madden, Paparo \& Schwartz, 1968; genital tract: Abdul-Karim \& Bruce, 1973). Microspheres with diameters of between 15 and $40 \mu \mathrm{m}$ have been used in these studies since it is most unlikely that microspheres with a diameter of more than $15 \mu \mathrm{m}$ can pass through ordinary capillaries. 
In the present study, no microspheres passed into the ovarian venous blood using the Type II perfusions. The percentage of passage could only be roughly estimated with this type of perfusion procedure, however, since all microspheres injected into the aorta did not pass into the ovarian arteries and the blood in the ovarian veins may have originated from other tissues than the ovary. In order to measure more accurately the microsphere passage, a Type III perfusion system was used. With this system, ovaries are exclusively supplied and drained by vessels in their vascular pedicles. No microspheres passed through in approximately $50 \%$ of both types of ovaries studied; the number of microspheres passing through the remainder was very low. Of the microspheres passed, none was more than $15 \mu \mathrm{m}$ in diameter. The intravasal trapping of the microspheres could be verified on histological examination.

In contrast to the Type II perfusion preparation, the Type III did not respond to a vaso-active drug such as norepinephrine, which may be due to hypoxic damage of the smooth muscle cells of the ovarian vessels. When a similar ovarian preparation was perfused in a perfusion apparatus with oxygenated perfusion fluid, norepinephrine caused a prompt and marked reduction of the flow rate (P. O. Janson and G. Selstam, unpublished observations). The Type III preparation was denervated, had a high flow rate, and did not respond to papaverine, indicating a dilated vascular bed. It seems very unlikely that arterio-venous shunts would be concealed in this preparation.

The blood flow of the CL is reported to be very high during pseudopregnancy (Novy \& Cook, 1973). If luteolysis is caused by a vascular mechanism associated with a redistribution of blood flow from the CL through arterio-venous shunts, a large flow rate in such vessels would be expected. In the present study, no difference in the passage of microspheres was found between ovaries with CL of different ages and the number of microspheres which achieved such a passage was very small. Thus, our observations do not support the view that arterio-venous shunts take part in blood flow regulation during the luteal cycle. Luteolysis might still be associated with a vascular mechanism, in which case ovarian blood flow changes might be regulated by nervous or humoral factors acting at a precapillary level on other vessels than arterio-venous shunts.

In the morphological studies of Reynolds (1950) passage of viscous vinylite was observed from the arterial to the venous side of the rabbit ovary. No information concerning perfusion pressure was given. In the present study, a great number of microspheres passed into the venous effluent at high and unphysiological perfusion pressures. Histological examination of the ovary after high pressure perfusion with a blood cell suspension revealed interstitial bleeding and the passage of microspheres at high pressures was probably due to vascular damage.

The present study gives no evidence for arterio-venous shunts of functional importance either in follicular or luteal ovaries. Low arterio-venous difference in $\mathrm{O}_{2}$ tension, which has been taken as a fact favouring the existence of arteriovenous shunts in the ovary, is per se no evidence for shunts. A high rate of blood flow and/or low $\mathrm{O}_{2}$ extraction by the ovary, can explain low arterio-venous $\mathrm{O}_{2}$ difference.

The fact that indirect and direct measurements of ovarian blood flow have 
shown large differences in results must be explained by factors other than arterio-venous shunts. One possibility is that the surgical procedures involved in the direct measurements have a marked influence on the blood flow. Another possibility is that certain indirect methods (clearance methods and indicator fractionation techniques) have included methodological errors due to heterogeneity and uneven perfusion of the ovarian tissues or peculiarities in the affinity of indicators to the ovary. Studies are in progress in this laboratory to analyse these possibilities.

\section{ACKNOWLEDGMENTS}

This research was supported by grants from the Swedish Medical Research Council (B74-03X-27-10C), The National Institutes of Health, USPH (5 RO1 HD0295-06), The Faculty of Medicine, University of Göteborg and Göteborgs Läkaresällskap. We are indebted to Assistant Professor Bernt Boeryd for performing the histological examinations. Valuable technical assistance was given by Miss Stina Öberg and Miss Britt-Marie Johansson.

\section{REFERENCES}

ABduL-Karim, R. W. \& BRUCE, N. (1973) Blood flow to the ovary and corpus luteum at different stages of gestation in the rabbit. Fert. Steril. 24, 44.

Ahrén, K., Janson, P. O. \& Selstam, G. (1971) Perfusion of ovaries in vivo and in vitro. Acta endocr., Copenh., Suppl. 158, 285.

Ahrén, K., Janson, P. O. \& Selstam, G. (1973) Passage of microspheres in follicular and luteal rabbit ovaries. Acta physiol. scand., Suppl. 398, 100.

Brown, B. W., Hales, J. R. S. \& MatTner, P. E. (1973) Gyclic changes in blood flow in the genital tract of the ewe. Proc. 5th ann. Conf. Austral. Soc. Reprod. Biology, 61 .

GiLlet, J. Y. (1971) La microvascularisation de l'ovaire. Gynéc. Obstét. 70, 251.

Goding, J. R., Baird, D. T., Cumming, I. A. \& MaGracken, J. A. (1971) Functional assessment of autotransplanted endocrine organs. Acta endocr., Copenh., Suppl. 158, 169.

Grim, E. \& LiNDSETH, E. O. (1958) Distribution of blood flow to the tissues of the small intestine of the dog. Univ. Minn. med. Bull. 30, 138.

HARPER, M. J. K. (1963) Ovulation in the rabbit: the time of follicular rupture and expulsion of the eggs, in relation to injection of luteinizing hormone. F. Endocr. 26, 307.

McCracken, J. A., Baird, D. T. \& Goding, J. R. (1971) Factors affecting the secretion of steroids from the transplanted ovary in the sheep. Recent Progr. Horm. Res. 27, 537.

Madden, R. E., Paparo, A. \& Schwartz, M. (1968) Limiting vascular diameters in various organs. Archs Surg. 96, 130.

MatTNER, P. E. \& Thorburn, G. D. (1969) Ovarian blood flow in sheep during the oestrous cycle. F. Reprod. Fert. 19, 547.

Novy, M. J. \& Cook, M. J. (1973) Redistribution of blood flow by prostaglandin $F_{2 \alpha}$ in the rabbit ovary. Am. 7. Obstet. Gynec. 117, 381.

Pharriss, B. B. (1970) The possible vascular regulation of luteal function. Perspect. Biol. Med. 13, 434.

PitPer, J. \& Rosell, S. (1961) Attempt to demonstrate large arterio-venous shunts in skeletal muscle during stimulation of sympathetic vasodilator nerves. Acta physiol. scand. 53, 214.

Reynolds, S. R. M. (1950) The vasculature of the ovary and ovarian function. Recent Progr. Horm. Res. 5,65 .

Setchell, B. P. (1969) Discussion to McCracken, J. A. \& Baird, D. T.: The study of ovarian function by means of transplantation of the ovary in the ewe. In The Gonads, p. 203. Ed. K. W. McKerns. Appleton-Century-Crofts, New York.

WURTMAN, R. J. (1964) An effect of luteinizing hormone on the fractional perfusion of the rat ovary. Endocrinology, 75, 927. 